\title{
Cell-to-cell transport in viral families: faster than usual
}

\author{
M. LABUDOVA
}

Institute of Virology, Biomedical Research Centre Slovak Academy of Sciences, Dúbravská cesta 9, 84505 Bratislava, Slovak Republic

\begin{abstract}
Summary.-The most frequent way of virus dissemination is through the canonical receptor-mediated pathway. However, when unfavorable conditions, such as presence of antibodies appear, the viruses use more peculiar routes of transmission to protect themselves. Here we describe most of the routes, from syncytia formation, tunneling nanotubes and filopodia, through immunological and virological synapses to actin comets formation. We describe the cell-to-cell transport in different viral families to show that this way of virus distribution is present in almost all the mammalian virus families and is not as uncommon as it was thought. The knowledge of the ways of viral transport might lead us to exploit more successful therapeutic approaches and fight the most threatening diseases.
\end{abstract}

Keywords: cell-to-cell transmission; tunneling nanotubes; viral synapses; filopodia; actin comets

\section{Introduction}

Every action of the individual cell depends on communication with neighboring cells. Most of the communications are provided by different types of protrusions. Protrusions are present in different tissues from different organisms and are characteristic for distinct functional or structural properties. More efficient spread of the virus, than classical spread by receptor recognition, is direct cell-cell contact (Jolly et al., 2004; Mcdonald et al., 2003). Numerous studies have showed cellular protrusions mediated virus transfer for many viruses, including human

E-mail: virulama@savba.sk; phone: +421-2-59302-439.

Abbreviations: BoHV-1 = bovine herpesvirus 1; BVDV = bovine viral diarrhea virus; Env = envelope protein; gE = BoHV-1 glycoprotein gE; HCV = hepatitis C virus; HHV-1 = human alphaherpesvirus 1 (herpes simplex virus 1 ); HIV-1 = human immunodeficiency virus type 1; ICAM = intercellular adhesion molecule; JEV = Japanese encephalitis virus; $\mathrm{K1}$ = keratin 1; LCMV = lymphocytic choriomeningitis virus; LFA-1 = lymphocyte function-associated antigen 1 ; MARV = Marburg virus; $M V$ = mature virus; $\mathrm{PRRSV}$ = porcine reproductive and respiratory syndrome virus; SuHV-1 = suid alphaherpesvirus 1 ; TNT = tunneling nanotubes; Us3 = tegument protein Us3 kinase; VACV = vaccinia virus; VP26 = BoHV-1 structural protein VP26; VS = virological synapses; $\mathrm{WV}=$ wrapped virus
T-cell leukemia virus type I (HTLV-1) (Van Prooyen et al., 2010), murine leukemia virus in living cells (Sherer et al., 2007), Marburg virus (Kolesnikova et al., 2007), African swine fever virus (Jouvenet et al., 2006) herpes viruses (Ady et al., 2016; Favoreel et al., 2005; Gill et al., 2008), influenza A viruses (Kumar et al., 2017; Roberts et al., 2015) and human immunodeficiency virus type 1 (HIV-1) (Sowinski et al., 2008). Cell-associated transmission is considered more rapid and efficient because it omits rate-limiting steps of cell-free spread: the release of virus particles, diffusion and entry occurs quickly at cell-cell contacts sites. What more, the viruses that utilize tight and adherence junctions for their transport are protected from the effect of neutralizing antibodies and other immune system components.

Filopodia as one of the earliest protrusions recognized (Gardel et al., 2010; Jacquemet et al., 2015), are actin-based protrusions observed at the leading edge of the migrating cells. First of all, filopodia "scan" the substrate followed by extension of lamellipodia toward the stabilized filopodia (Albrecht-Buehler, 1976; Trelstad et al., 1967). However, it was proved that the formation of filopodia did not always correlate with cell migration but instead correlated with intercellular signaling (Miller et al., 1995).

Cytonemes are defined as "filopodia of a special type" reaching up to $700 \mu \mathrm{m}$ in length in Drosophila (RamirezWeber and Kornberg, 1999). Cytonemes connect cells sepa- 
rated not only by distance but by other (non-participant) cells in the tissues, and are believed to deliver signaling molecules and their receptors between signal-sending and -receiving cells. Also cytonemes and tunneling nanotubes were found to form between cells in culture cells, allowing trafficking of vesicular organelles (Rustom et al., 2004). Cytonemes mediate the delivery of specific signaling ligands (morphogens) and their receptors to allow specific signal transduction between cell types that are far apart from each other, often separated by large numbers of intervening cells (Kornberg and Roy, 2014). As filopodia, cytonemes contain actin and need regulators of actin dynamics for their formation (Roy et al., 2014).

Tunneling nanotubes (TNT) were shown to form de novo between previously unconnected cells by extension of protrusions (Rustom et al., 2004) or by dislodgement of two previously-attached cells, which left TNTs behind (Sowinski et al., 2008). The name tunneling nanotube is taken from both their original discovery diameter size (50-200 nm), and also their tunneling ability in the extracellular matrix. They are thin tube structures protruding from one cell and connecting with the other to form a nanotubular network (You et al., 2014). These structures are filled with cytoskeletal filaments, like actin, microtubules and motor proteins. Usually, smaller $(<100 \mu \mathrm{m})$ tubes of TNTs contain F-actin while thicker tubes $(>100$ $\mu \mathrm{m})$ contain both F-actin and microtubules (Rustom et al., 2004; Sowinski et al., 2008; Wang et al., 2010). TNTs, by character of the connection can be divided into TNTs with open-end and closed-end. Open-ended TNTs support the continuity of cytoplasm between two cells allowing thus calcium signaling, free diffusion of membrane proteins or transport of large organelles such as mitochondria. Closed-ended TNTs do not propagate calcium signals nor free diffusion of membrane proteins (Gerdes and Carvalho, 2008). However, it was observed that the TNT tips of one cell adheres to the other surface of the other cell. These structures mostly contain actin and are found in cultured cells where they were observed to be loose in the media without attachment to the surface as well as attached (Naphade et al., 2015). However, the constituent cytoskeleton, actin or microtubule, present in TNTs determines the type of molecular motors (myosine, kinesins, dyneins), and thus specific cargoes, to be trafficked between cells.

Commonly, the TNTs are formed or modified by the influence of the stress, including $\mathrm{H}_{2} \mathrm{O}_{2}$, $\mathrm{UV}$, virus infection, prion aggregation, serum starvation and high glucose concentration (Thayanithy et al., 2014b; Wang and Gerdes, 2015; Wang et al., 2011). Typically, stressed cells form TNTs to reach out to healthy cells, indicating that TNT formation may be a mechanism that helps protect cells from death. In the culture of rat hippocampal neurons and astrocytes, p53 and its downstream effectors (Egfr, Akt, phosphoinositide 3-kinase, and mTOR) are critical for TNT formation (Wang et al., 2011), although its requirement is likely cell type-specific (Andresen et al.,2013). These structures are critical requirement for development, and tissue homeostasis and regeneration. TNTs can also contribute to cellular differentiation and reprogramming by providing a highway to transfer cellular components from one cell to another cell (Takahashi et al., 2013). However, the TNTs also contribute to spread of the tumors (Thayanithy et al., 2014a), progression of neurodegenerative diseases and transfer of bacteria, viruses and prions (Dubey and Ben-Yehuda, 2011; Gousset et al., 2009; Roberts et al., 2015; Sowinski et al., 2008).

Microtubules-based nanotubes (MT-nanotubes) mainly contain microtubules and do not require regulators of the actin cytoskeleton for their formation. MT-nanotubes utilize components of cilia formation (e.g. intraflagellar transport (IFT) proteins) although they lack other characteristics of cilia (such as acetylated tubulin) (Inaba et al., 2015).

Synapses transmit cell-cell signal through the extracellular space, relying on mechanism of ligand-receptor signaling across tight cell-cell junctions. During formation of the immunological synapses between T-cells and antigen-presenting cells, filopodia precede the formation as a full synaptic cleft and might even persist as functional "probes" operating in the cell-cell interface (Williams et al., 2007). Crucial transition from a filopodial intermediate to a tighter cell-cell contact depends on the recruitment of additional adhesion proteins and intracellular adaptors. For example, clusters of E-cadherin are recruited to establish adherence junctions, Syn-CAM or neuroligin are needed for neurological synapses and ICAM-1, LFA1 for immunological synapses (Sherer and Mothes, 2008). In the absence of specialized epithelial or synaptic adhesion proteins, a filopodial intermediate is stabilized to form a prolonged and elongated filopodial bridge (Sherer and Mothes, 2008). Pseudorabies virus and herpes simplex virus spread throughout the nervous system by means of neuronal synapses. HIV-1 and HTLV-1 use "virological synapses" in infected lymphocytes so named in analogy to immunological synapses (Igakura et al., 2003).

The most specific virus cell-to-cell transport, actin comets or tails, are provided by Poxviruses. Thanks to this rapid cell-to-cell spread they replicate and spread extremely rapidly in the epidermis and endothelium. We will discuss this unique transport in detail further on in the Poxviridae chapter.

Also, syncytia formation can be classified as a special cell-to-cell transmission. Any viruses that are able to induce fusion machinery in the infected cells especially on basolateral surface of polarized epithelial cells and can 
undergo $\mathrm{pH}$-independent fusion at the plasma membrane are able to mediate cell-cell fusion and form syncytia. Some of the families causing formation of syncytia are Herpesviridae, Paramyxoviridae and Coronaviridae (Sattentau, 2008)

\section{Cell-to-cell transport in viral families}

\section{Herpesviridae}

Alphaherpesviruses are able to spread across the junctions between the membranes of cells, by fusion of adjacent cells or on long distances along neurons (Nobiron et al., 2003).

Bovine herpesvirus 1 (BoHV-1) is a widespread bovine pathogen, a member of the Varicellovirus genus of the subfamily Alphaherpesvirinae. BoHV-1 shares many features with human herpesviruses, such as herpes simplex virus 1 and varicella-zoster virus (Muylkens et al., 2007). Due to its strong immunomodulatory properties, BoHV-1 is an interesting model for studies of viral immune evasion and cell-to-cell spread (Tyborowska et al., 2000). BoHV-1 has a restricted host range with cattle as the natural host; it is propagated in cells of bovine origin, although it has recently been shown to also infect human tumor cells (Cuddington and Mossman, 2014).

It utilizes various types of intercellular projections. In the infected cells, quantification of intercellular extensions showed a significant increase in the number of projections. Different structural viral proteins (glycoprotein gE, tegument protein Us3 kinase, capsid structural protein VP26) individually or as parts of an assembled particle were present both inside and on the surface of nanotubes and also in bubble-like vesicles (gondolas) formed from nanotubes. Protein VP26 migrated mostly in compact structures, while gE and Us3 were mostly visible in gondolas (Merwaiss et al., 2019). Unenveloped capsids and glycoproteins were during axonal transport transported separately and assembled into virions at the destination (Thomas et al., 2009) (Fig. 1).

Suid alphaherpesvirus 1(SuHV-1) or Pseudorabies virus (the subfamily Alphaherpesvirinae, the genus Varicellovirus) causes Aujeszky's disease or Pseudorabies. It is linear double-stranded DNA virus with wide host range infecting numerous species of domestic and wild animals, with pigs being the natural host and reservoir (Sun et al., 2016) In the SuHV-1 studies, it was for the first time shown that Us3 protein kinase, a highly conserved protein among the herpesviruses, stimulated the formation of long intercellular projections. The activity of Us3 was crucial for the formation of nanotubes. SuHV-1 infected cells formed nanotubes and the presence of intact virions was clearly visible inside nanotubes. The nanotubes formed by SuHV1 infected cells were remarkably stable compared to most TNTs described (Favoreel et al., 2005; Jansens et al., 2017). The Us3 induced TNTs contained stabilized microtubules and the virus particles were individually transported in membrane-bound vesicles and released along the TNTs and at the contact area between a TNT and adjacent cell. Contact between Us3-induced TNTs and acceptor cells was very stable and rich for components of adherens junctions such as beta-catenin or E-cadherin at the contact area (Jansens et al., 2017) (Fig. 1).

Human alphaherpesvirus 1 or herpes simplex virus 1 (HHV-1) utilizes a specific cell-to-cell transmission system-formation of syncytia. Protein tyrosine phosphatase (PTP1B) is the first host factor identified to be specifically required for cell-to-cell spread, and it may be a therapeutic target for preventing HSV-1 diseases (Carmichael et al., 2018) (Fig. 1).

\section{Poxviridae}

Vaccinia virus (VACV) as a member of the Poxviridae family has a unique way of transmission, forming of actin comets. This is a very complex mechanism, that includes great regulation and is mediated and fine-tuned by a multitude of host factors (Newsome and Marzook, 2015).

Mature virus (MV) particles are formed in the perinuclear replication center called virus factory. These particles are formed by single membrane derived from the endoplasmatic reticulum and over 100 viral proteins (Resch et al., 2007). In early endosomes and trans-Golgi network compartments, a subset of MV acquires two additional membrane layers to form wrapped virus (WV). WV is the only viral form that is able to promote actin nucleation. By adding additional membranes WV acquires additional membrane associated proteins (WV-specific proteins), such as A36, F12 and E2 functioning in recruitment and stabilization of microtubule motor complex kinesin-1. This interaction drives the viral particle from the virus factory to the cell periphery (Carpentier et al., 2015; Dodding et al., 2011). By cooperation of proteins carried by the virus and cellular proteins, the virus is transported on to extracellular side of the membrane. Actin nucleation by extracellular WV is executed by the cellular actin nucleator, the Arp2/3 complex to promote de novo seeding of actin filaments at $70^{\circ}$ branch points on existing actin filaments. Following nucleation, actin polymerization is in a constant state of movement; as rapidly as actin is nucleated at the cytoplasmic/virus interface and filaments extend, actin polymers are disassembled, giving rise to a characteristic comet morphology (also referred to as actin „tails“). Usually, cells infected with VACV show 5-50 virus-associated actin comets of about $3.5 \mu \mathrm{m}$ in length, 

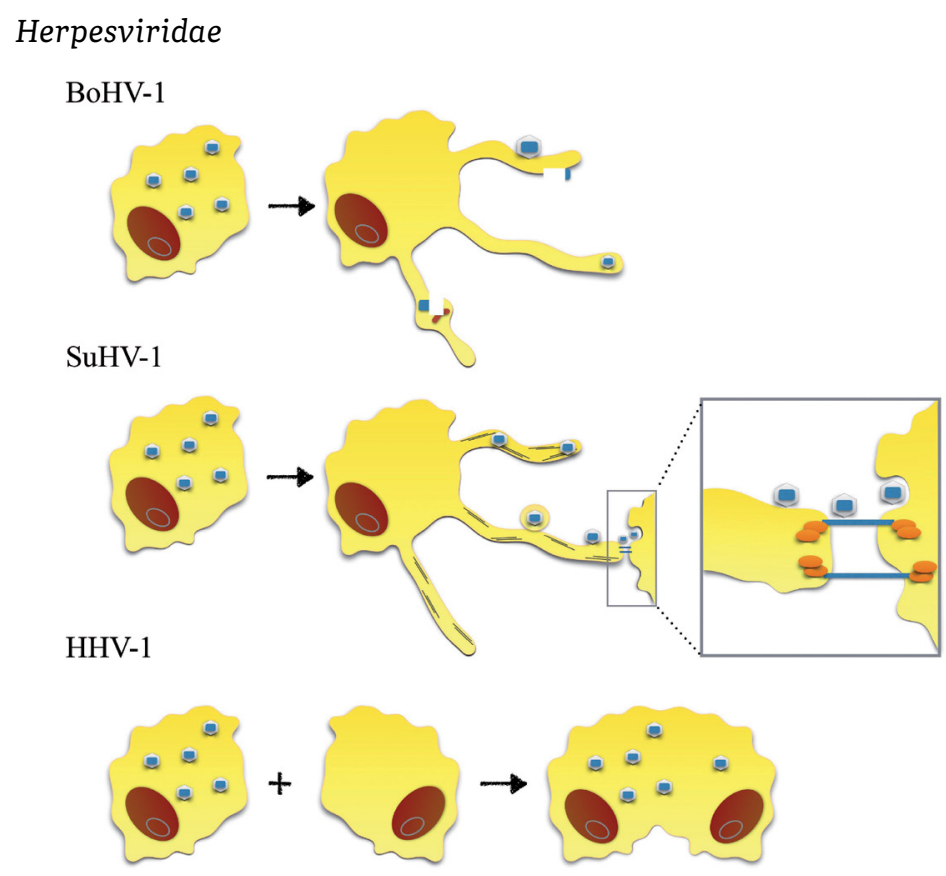

\section{Poxviridae}

VACV
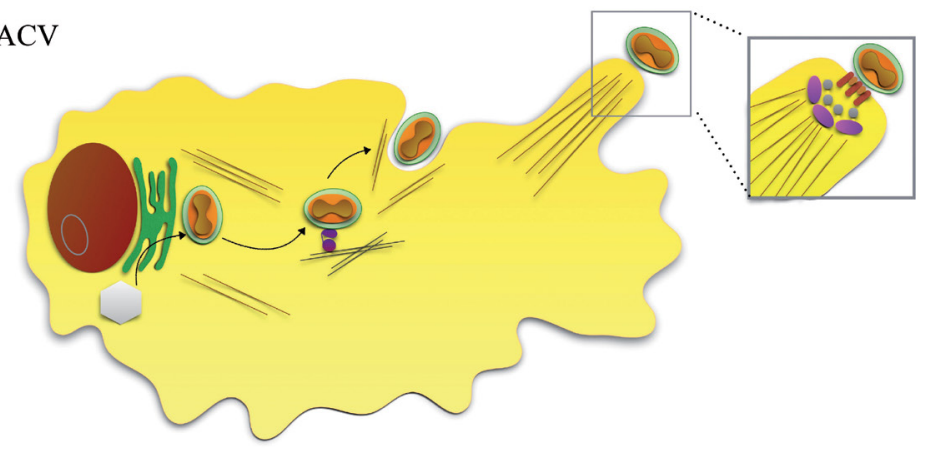

\begin{tabular}{|ll|}
\hline & VP26 \\
Us3 \\
gE \\
\hline & microtubules \\
$\beta$-catenin \\
E-cadherin \\
MV \\
WV \\
\hline actin \\
kinesin-1 \\
A36R \\
Arp2/3 \\
\hline
\end{tabular}

Fig. 1

Different types of cell-to-cell transports in DNA viruses

Herpesviridae: In BoHV-1 infected cells the significant increase in number of projections is induced. Capsid structural protein VP26 migrates in compact structures, while glycoprotein gE and tegument protein Us3 kinase is mostly present in gondolas (bubble-like vesicles). They utilize different types of intercellular projections. SuHV-1 stimulates the formation of long intercellular projections. Virions are present inside the nanotubes. TNTs contain stabilized microtubules. Virus particles are individually transported in membrane bound vesicles and released along TNTs and at contact with adjacent cell. Contacts are very stable and rich for components of adherens junctions such as beta-catenin or E-cadherin at the contact area. HHV-1 utilizes for its transmission the formation of syncytia. Poxviridae: VACV utilizes the formation of actin comets. Mature virions (MV) are formed in perinuclear replication center. In trans-Golgi network, MVs acquire additional membrane layers to form wrapped virus (WV). WVs associated with kinesin-1 motor are moved to the cell periphery and virus is transported on to extracellular side of the membrane. Actin nucleation is executed by Arp2/3 complex to form actin "tails" that propel WV to the neighboring cell.

although there is great variation between cell types (Dodding et al., 2011). At any point in time, 20-30\% of cellassociated extracellular virus will be adjacent to an actin comet (Humphries et al.,2012). Actin comets on the apical surface of isolated VACV-infected cells manifest as long virus tipped cytoplasmic extensions to promote delivery of WV to adjacent cells, perhaps by overcoming the cortical actin-reinforced plasma membrane of adjacent cells. Actin-based motility is concentrated at the cell-to-cell junctions (Rietdorf et al., 2001) (Fig. 1). 


\section{Retroviridae}

In retroviruses, the induction of synapse-like structures facilitating cell-to-cell spread is triggered by the interaction of the viral glycoprotein (Env) with specific host receptors. Blocking the Env-cell receptor interaction abolishes cell-to-cell transmission (Jolly and Sattentau, 2004; Sherer et al., 2007).

Human immunodeficiency virus 1 (HIV-1) is the etiological agent of acquired immune deficiency syndrome(AIDS) (Barre-Sinoussi et al., 1983). It infects cells by multiple mechanisms, either as cell-free or cell associated particles (Casartelli, 2016). HIV-1 infection is more efficient when the virus is transmitted through direct cell contacts $(\mathrm{Br}-$ acq et al., 2018).

Viral synapses (VS) are direct adhesive cell-cell contact structures that can be formed between HIV-1 infected and uninfected $\mathrm{CD}^{+} \mathrm{T}$ cells. The T cell VS is characterized as an actin-dependent polarization of viral proteins Env and Gag on the infected cells and CD4 receptor on the uninfected cell, forming cell-to-cell contact region(Jolly et al., 2004). Other molecules, such as intercellular adhesion molecules (ICAM) 1 and 3 and LFA-1 may further stabilize the VS (Jolly et al., 2007; Jolly and Sattentau, 2004). Cell-tocell infection, at least in vitro is more efficient (Chen et al., 2007; Sourisseau et al., 2007), enables the resistance of the virus to certain classes of antiviral drugs (Sigal et al., 2011; Titanji et al., 2013) and to broadly neutralizing antibodies (Li et al., 2017; Reh et al., 2015). What more, cell-to-cell transmission of HIV-1 is an important route that leads to the establishment of latent infection (Pedro et al.,2019).VS can also take place between adjacent cells or on relatively long distances such as in the case of filopodia (Sherer et al., 2007; Sowinski et al., 2008).

In several studies a model of cell-to-cell transmission of HIV-1 initially transferred across the VS in a co-receptor independent manner into trypsin-resistant endocytic compartments within the HIV-1 uninfected target CD41 ${ }^{+} \mathrm{T}$ cells is supported (Chen et al., 2007; Dale et al., 2011; Sloan et al., 2013). Time-lapse imaging studies showed interaction between Env and CD4 prior to the recruitment of Gag to the cell-cell contact region (Hubner et al.,2009), indicating that Env initially functions as an adhesion molecule already during formation of VS (Chen, 2012).

In HIV-1 also another type of cell-to-cell type infection can occur. This mechanism is called trans-infection and it is provided by infectious synapse. The infectious synapse forms when the virus is captured by a cell without itself becoming infected and directs the intact particle to the target cell through the cell-cell contact (Kijewski and Gummuluru, 2015). Trans-infection is usually associated with transmission from myeloid antigen presenting cells to $\mathrm{CD}^{+} \mathrm{T}$ cells, such as macrophages and dendritic cells, but can occur between different other cell types (Pedro et al., 2019). Usually, HIV-1 is captured by surface molecules of APC, such as C-type lectin SIGLEC-1 and stored in nonlysosomal compartments where it avoids degradation and antibody neutralization (Gummuluru et al., 2014). After this, interaction between two cells mediated by ICAM-1 and LFA-1 are arranged to form infectious synapse (Rodriguez-Plata et al., 2013). Meanwhile, complimentary processes accompanied by the cytoskeleton reorganization, are occurring in the $\mathrm{CD} 4^{+} \mathrm{T}$ cell. Variety of molecules are directed to the site of contact including CD4, CXCR4 and CCR5 and the receptors required by HIV-1 entry (Pedro et al., 2019).

Also synapse independent cell-cell transmissions are utilized by HIV-1, such as phagocytosis, where macrophages phagocytosing dying HIV-1-infected $\mathrm{CD}^{+} \mathrm{T}$ cells subsequently become infected (Baxter et al., 2014); syncytium formation, which occurs as a consequence of HIV-1-gp120 on infected cells interacting with CD4 on uninfected cells resulting in the fusion of the two cell membranes (Bracq et al., 2018); tunneling nanotubes, where the virus usually transfers through the nanotubes inside the endosomes (Kadiu and Gendelman, 2011a,b); and transcytosis (Pedro et al., 2019).

The Nef (negative regulatory factor of HIV) HIV-1 accessory protein is critical for HIV-1 pathogenesis and can self-disseminate in culture via TNTs. Nef can regulate Myosin-X (Myo10), a TNT inducer in neuronal cells, expression, thereby inducing TNT formation, resulting in its own transfer from macrophages to T cells (Uhl et al., 2019).

Transcytosis is a process where cells, usually mucosal epithelial cells, capable of internalizing viral particles into vesicles at the apical surface, transport the vesicles to the basal layer and transmit them to $\mathrm{CD} 4^{+} \mathrm{T}$ cells (Anderson, 2014; Kinlock et al., 2014).

During HIV-1 and tuberculosis co-infection, the tuberculosis-associated microenvironment triggers IL10/STAT3-dependent tunneling nanotube formation in macrophages and promotes thus HIV-1 dissemination (Souriant et al., 2019) (Fig. 2).

\section{Flaviviridae}

Hepatitis C virus (HCV), is a hepatotropic virus, resulting in acute and chronic hepatitis, cirrhosis, and hepatocellular carcinoma (HCC) in humans. It contains a single-stranded and positive-sense RNA genome and a cellular membrane-derived envelope. The viral polyprotein is cleaved into structural (core, E1, E2, and p7) and nonstructural (NS) viral proteins (NS2, NS3, NS4A, NS4B, NS5A, and NS5B) (Lindenbach and Rice, 2005). HCV infection occurs in two different forms, cell-free and cell-to-cell transmission. Cell-free transmission is the major route 
Retroviridae

(a)

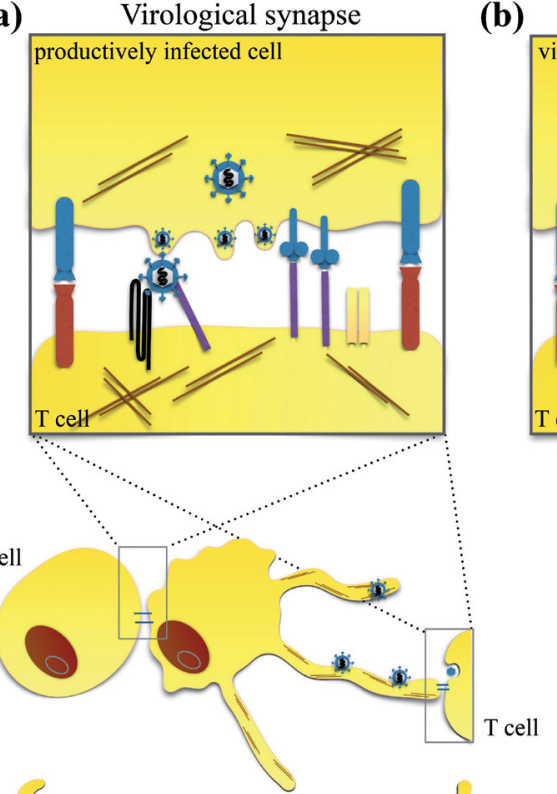

(c)

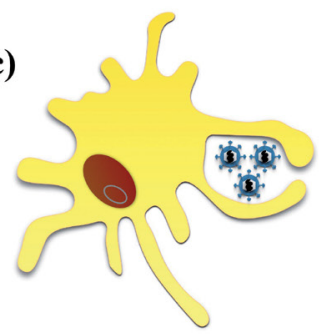

(d)

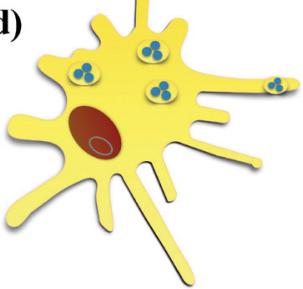

(e)

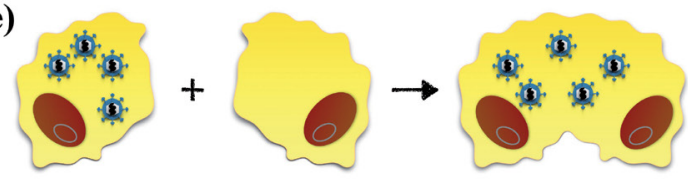

(f)

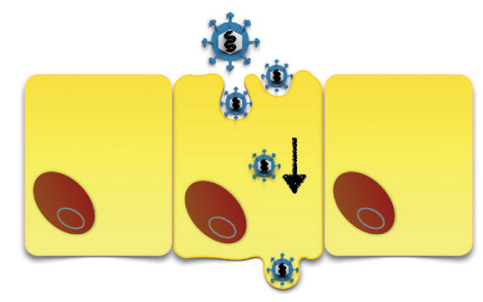

(b) Infectious synapse

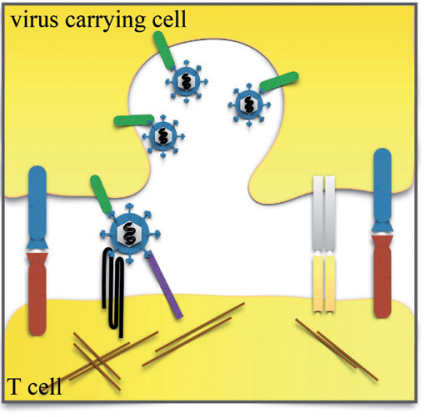

Fig. 2

Different types of cell-to-cell transports in Retroviruses HIV-1 uses, for its spread, virological synapses (a) that form cell-to-cell contacts through ICAM 1, 3 and LFA-1 molecules. CD4 interacts with Env, viral envelope protein. VS can take place between adjacent cells or on relatively long distances such as in the case of filopodia. The second type of infection by cell-to-cell contacts is by infectious synapse (b) also named trans infection. It occurs, when cell with captured virion (but not infected) directs the intact particle though the cell-cell contact on to the uninfected cell. Virion is stored in nonlysosomal compartments captured by SIGLEC-1 molecules. Infection synapse is formed by interaction of ICAM- 1 and LFA1 molecule as in virological synapse. Other types of cell-to-cell transmission, such as phagocytosis (c), tunneling nanotubes, where the virus travels inside the endosomes (d), syncytium formation (e) and transcytosis, where the virion enters apical surface and is transported to the basal layer $(\mathbf{f})$, are utilized.
(>90\%) of HCV infection, which can be blocked by E1/E2specific monoclonal antibodies. Cell-cell transmission is responsible for the spread of HCV between neighboring cells and is not affected by HCV-neutralizing antibodies (Brimacombe et al., 2011; Timpe et al., 2008). Thus, it is thought that cell-to-cell transmission may contribute to the escape of the host immune response against HCV, resulting in persistent infection. HCV utilizes virological synapses or membrane nanotubes as a way of cell-to-cell transmission (Carloni et al., 2012).
The cell-to-cell transmission of HCV depends on the expression of two cellular proteins, also functioning as post-attachment receptors for the entry of free virus, claudin-1 and occludin present in the junction cell-cell contacts (Brimacombe et al., 2011; Carloni et al., 2012; Timpe et al., 2008; Witteveldt et al., 2009). The host cell molecule CD81 and the tight junction protein claudin 1 (CLDN1) are critical factors for HCV entry. The presence of soluble CD81 and anti-CD81 abrogated cell-free infection of Huh-7.5 cells and partially inhibited cell-cell transfer 
of infection. CD81-negative HepG2 hepatoma cells were resistant to cell-free virus infection, however they could be infected after co-culturing with cells infected with a different strain in the presence of neutralizing antibodies, confirming that CD81-independent routes of cell-cell transmission exist. Further experiments suggest that cell-cell transmission is dependent on CLDN1 expression. However, it is suggested that CLDN1 is required but that CD81-dependent and independent routes exist (Timpe et al., 2008; Witteveldt et al., 2009) (Fig. 3).

Bovine viral diarrhea virus (BVDV) infects cattle and causes major economic losses to the livestock industry. The viral particle is formed by lipid bilayer with protruding envelope glycoproteins $\mathrm{E}^{\text {rns }}$, E1 and E2, capsid protein C and the RNA genome (Callens et al., 2016; Thiel et al., 1991). E2 determines the cellular tropism and interacts with cellular receptors (Liang et al., 2003; Maurer et al., 2004).

In BVDV infected cells the main mechanism of propagation was antibody resistant spread (Merwaiss et al., 2019), referring to the cell-to-cell spread without leaving the cell. The presence of the CD46 receptor is necessary for both cell-free and cell-to-cell transmission (Brimacombe et al., 2011; Carloni et al., 2012; Timpe et al., 2008; Witteveldt et al., 2009). Also, the envelope protein E2 is required for cell-associated spread, what was proved by blocking the cell-to-cell transmission by soluble E2. A proposed mechanism of BVDV cell-to-cell transmission involves the egress of complete virus particles in exocytic vesicles and accumulation in the extracellular space at sites of cell-cell contact (Schmeiser et al., 2014). Envelope protein E2 attachment to the plasma membrane engages a cellular co-receptor on the target cell which mediates internalization of spreading virions by clathrin dependent endocytosis (Merwaiss et al., 2019) (Fig. 3).

The neurotropic Japanese encephalitis virus (JEV) causes Japanese encephalitis, an uncontrolled inflammatory disease of the central nervous system. It is a single stranded positive sense RNA virus encoding 3 structural proteins, capsid $(\mathrm{C})$, precursor of membrane protein and envelope protein (E) and 7 non-structural proteins (Misra and Kalita, 2010). The absence of E protein in JEV-infected microglia cells makes it impossible to form the virus particles. However, detection of intracellular dsRNA in microglia demonstrates a replicative form of JEV viral RNA. Viral RNA may be sufficient for cell-to-cell transmission and the recovery of infectious virus (Boyce and Roy, 2007; Yun et al., 2007). A cell-to-cell transmission of viral RNA is alternative mechanism enabling the generation of new virus particles (Zhong et al., 2013). Human microglia incapable to generate infectious virus particles and production of microglia-associated JEV by target cells depends on cell contact (Lannes et al., 2017). Microglia may use virological synapses or membrane protrusions such as nanotubes and/or filopodia structures. Virological synapses require the co-operation of adhesion molecules together with microtubules and actin cytoskeleton stabilization (Bracq et al., 2018). The transmission of JEV from microglia to target cells involves $\mathrm{CX}_{3} \mathrm{CR} 1-\mathrm{CX}_{3} \mathrm{CL} 1$ interaction. However, additional or alternative factors may be involved in transmission, since the antagonist of $\mathrm{CX}_{3} \mathrm{CR} 1 \mathrm{did}$ not completely abrogated the JEV transmission (Lannes et al., 2019). For instance, DC-SIGN expressed in human microglia (Lambert et al., 2008), promotes dendritic cell-to-T cell transmission of JEV (Wang et al., 2017) and mediates cellular modifications such as cytoskeleton remodeling promoting filopodia extension (Nikolic et al., 2011) (Fig.3).

\section{Togaviridae}

Some members of the Alphavirus genus are able to induce the formation of TNTs in several cell types. This induction of TNTs is dependent on both the E2 envelope glycoprotein and the $\mathrm{Cp}$ capsid protein, but the cellular pathways through which they act are still unknown (Martinez and Kielian, 2016). The intercellular extensions were long $(>10 \mu \mathrm{m})$, contained actin and tubulin, and formed flattened contacts with adjacent cells, however they did not mediate membrane or cytoplasmatic continuity between cells. The formation of TNTs did not require the virus receptor, or active particle budding, however it required the E2-capsid protein interaction and TNTs also formed in presence of structural proteins only (Martinez and Kielian, 2016) (Fig. 3).

\section{Arteriviridae}

Porcine reproductive and respiratory syndrome virus (PRRSV) is an enveloped positive stranded RNA virus. In infected pigs it mainly infects subsets of swine macrophages present in lungs and lymphoid organs (Labarque et al.,2000). A novel mechanism of antiapoptosis/necrosis in PRRSV infected cells was discovered. PRRSV infection induces increased formation of intercellular nanotube connections, and TNTs are determined to be involved in mitochondria transfer between infected and non-infected cells. More importantly, transfer of functional mitochondria through nanotubes rescued the host cell from apoptosis/necrosis in the early stage of infection by PRRSV. On the other hand, mitochondria were observed as a potential transporter of viral infectious materials for cell-to-cell spreading of the infection (Guo et al., 2018) (Fig. 3).

\section{Filoviridae}

Marburg virus (MARV) causes fulminant hemorrhagic disease in humans and non-human primates with high 
Flaviviridae

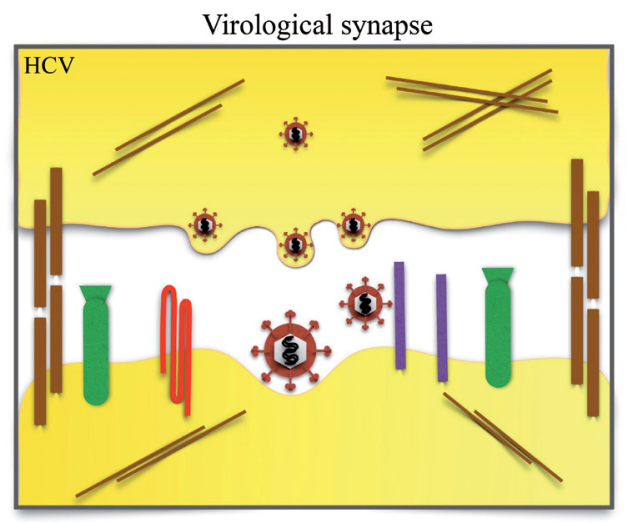

Egress from exocytic vesicles at cell-cell contact
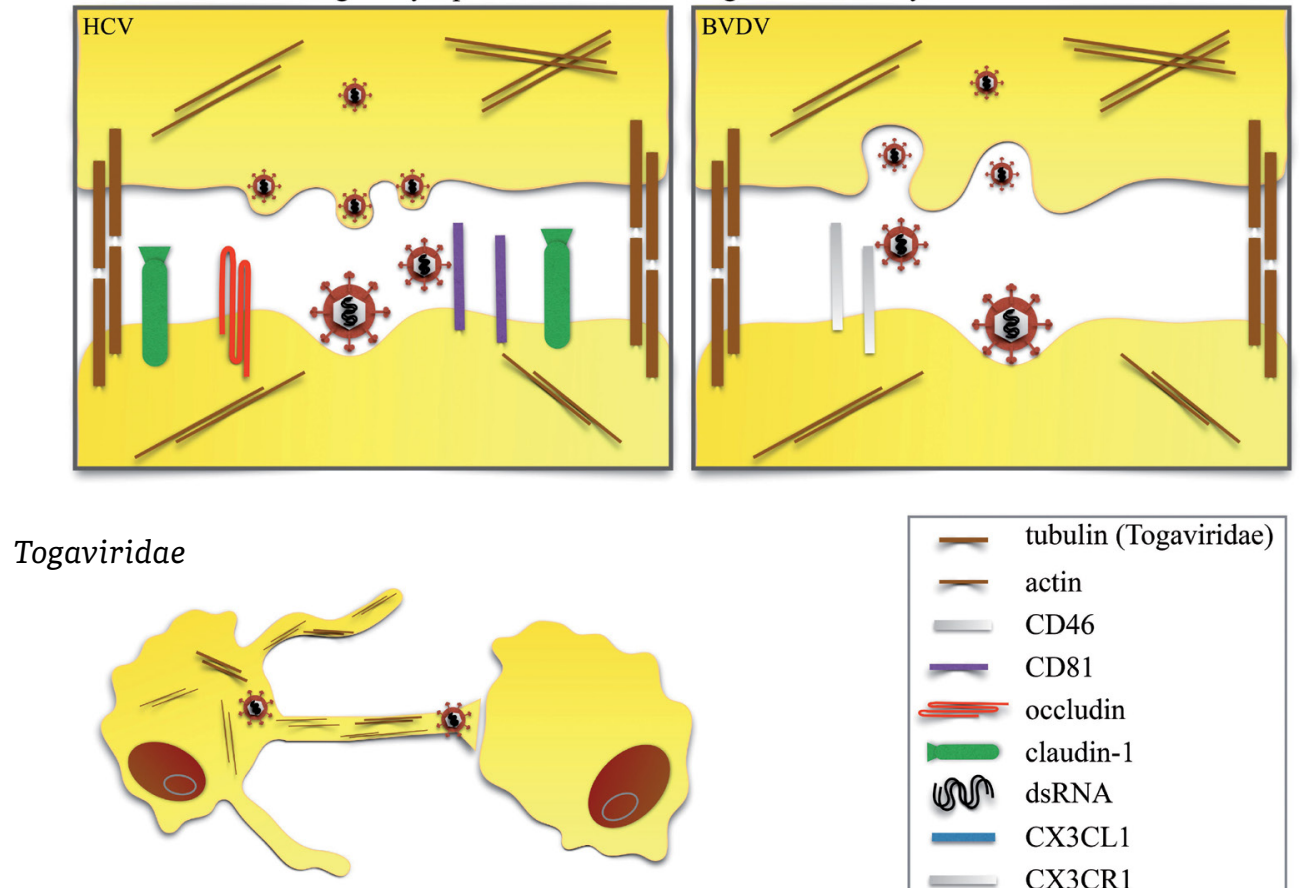

$\begin{array}{|ll|}= & \text { tubulin (Togaviridae) } \\ = & \text { actin } \\ & \text { CD46 } \\ & \text { CD81 } \\ = & \text { occludin } \\ & \text { claudin-1 } \\ \text { US } & \text { dsRNA } \\ = & \text { CX3CL1 } \\ = & \text { CX3CR1 } \\ = & \text { tight junctions }\end{array}$

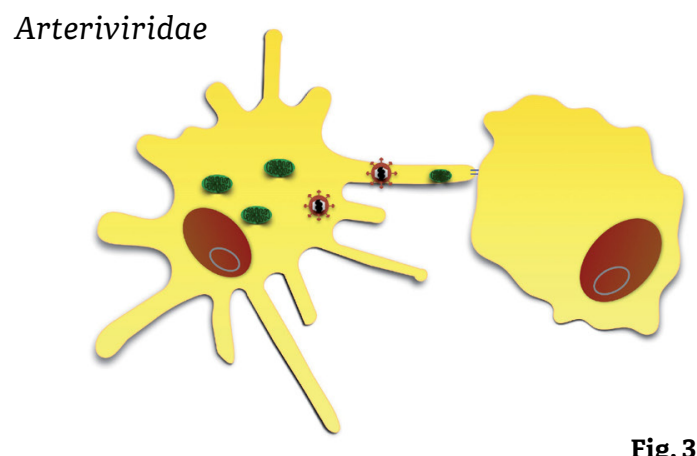

Fig. 3

Different types of cell-to-cell transports in RNA viruses with positive polarity

Flaviviridae: In HCV, cell-to-cell transmission depends on the post-attachment receptors claudin-1 and occluding, present in tight junctions cell-cell contacts, and host cell molecule CD81 that binds envelope protein E2. BVDV infection is mediated by egress of complete virus particles in exocytic vesicles and accumulation in the extracellular space at sites of cell-cell contact. Presence of CD46 is necessary for cell-to-cell spread. JEV uses virological synapses or membrane protrusions such as nanotubes and/or filopodia structures. Virological synapses require the co-operation of adhesion molecules together with microtubules and actin cytoskeleton stabilization and CX CR1CX ${ }_{3}$ L1 interaction. Viral RNA may be sufficient for cell-to-cell transmission. Togaviridae: The intercellular extensions contain actin and tubulin, and form flattened contacts with adjacent cells. There is no mediate membrane or cytoplasmatic continuity between cells. Arteriviridae: PRRSV infection induces increased formation of intercellular nanotube connections. TNTs are involved in the mitochondria transfer between cells.

mortality rates (Peters, 2005). It is a single-stranded negative-sense RNA virus encoding seven structural proteins, viral polymerase; VP35 and VP30 associated with nucleoprotein; glycoprotein present in viral envelope and mediating the viral entry and matrix proteins VP40 and VP24 playing a key role in virion assembly (Kolesnikova et al., 2002).
It is known that MARV is strongly associated with the actin cytoskeleton, which is essential for MARV release from the cell and the viral particles in the process of budding are associated with filopodia (Kolesnikova et al., 2007). VP40 transported in the multivesicular bodies to the place of virion completion is closely associated with filopodia. Filopodia thus can play a strategic role in the 
Filoviridae

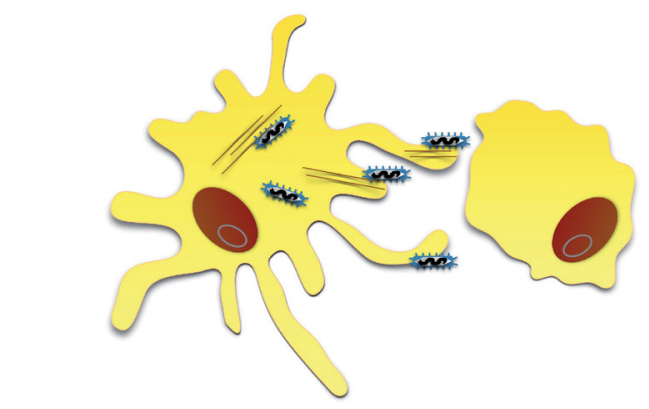

Orthomyxoviridae
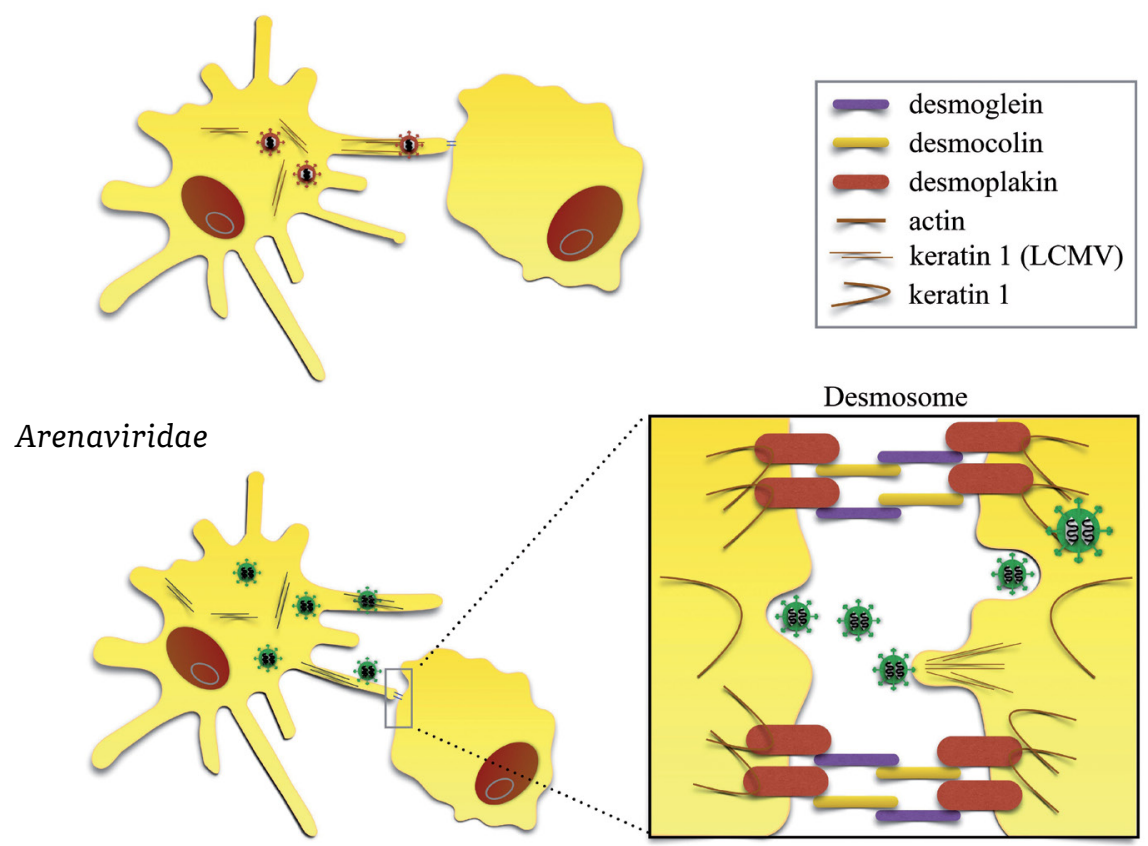

Fig. 4

Different types of cell-to-cell transports in RNA viruses with negative polarity

Filoviridae: MARV is strongly associated with actin. Virion completion is closely associated with filopodia. Orthomyxoviridae: IAV increases the frequency of nanotube formation. Viral components are present inside the nanotubes. Arenaviridae: LCMV nucleoprotein interacts with keratin 1(K1), which facilitates its transfer preferentially to the desmosomes, tight junctions consisting of desmoplakin, desmocolin and desmoglein strongly associated with keratin 1 . Here the virus crosses the intercellular space. LCMV virion components can also be transported along the nanotubes - inside and also in the extracellular space. LCMV might also utilize actin "tails".

spread of MARV in infected tissue because they can guide viral particles directly to new target cells (Kolesnikova et al., 2007). However, the direct cell-to-cell dissemination has not been proved yet (Fig. 4).

\section{Orthomyxoviridae}

Influenza A virus, contains a negative-stranded segmented RNA genome. In humans, it causes respiratory disease with epidemic to pandemic potential. Despite the presence of circulating protective levels of hemaggluti- nation-inhibiting antibodies, influenza viruses can still spread to cause disease. In the experiments with PR8 influenza A virus strain, the infection increased the frequency of nanotube formation, suggesting that the virus may utilize these cellular protrusions to its dissemination. Also, after the blocking the spread of the cell-free virus by Oseltamivir or neutralizing antibodies in the co-cultured infected and uninfected cells, the uninfected cell became infected. The nanotubes were observed to form between the infected and uninfected cells and the transfer of the viral components could be seen in these nanotubes. After 
Table. 1 Cell-to-cell transport in different viral families

\begin{tabular}{|c|c|c|c|}
\hline \multirow{2}{*}{ Family } & \multicolumn{2}{|l|}{ Example species } & \multirow{2}{*}{ Type of transport } \\
\hline & Name & Abbreviation & \\
\hline \multirow[t]{3}{*}{ Herpesviridae } & Bovine herpesvirus-1 & BoHV-1 & tunneling nanotubes \\
\hline & Suid alphaherpesvirus 1, pseudorabies virus & SuHV-1 & tunneling nanotubes \\
\hline & Human alphaherpesvirus 1, herpes simplex virus 1 & HHV-1 & syncytia \\
\hline Poxviridae & Vaccinia virus & VACV & actin comets \\
\hline \multirow[t]{5}{*}{ Retroviridae } & Human immunodeficiency virus & HIV & viral synapses \\
\hline & & & infection synapses \\
\hline & & & syncytia \\
\hline & & & tunneling nanotubes \\
\hline & & & transcytosis \\
\hline \multirow[t]{6}{*}{ Flaviviridae } & Hepatitis $\mathrm{C}$ virus & $\mathrm{HCV}$ & viral synapses \\
\hline & & & tunneling nanotubes \\
\hline & Bovine viral diarrhea virus & BVDV & exocytosis vesicles \\
\hline & Japanese encephalitis virus & JEV & viral synapses \\
\hline & & & tunneling nanotubes \\
\hline & & & filopodia \\
\hline Togaviridae & & & tunneling nanotubes \\
\hline Coronaviridae & & & syncytia \\
\hline Arteriviridae & Porcine reproductive and respiratory syndrome virus & PRRSV & tunneling nanotubes \\
\hline Paramyxoviridae & & & syncytia \\
\hline Filoviridae & Marburg virus & MARV & filopodia ??? \\
\hline Orthomyxoviridae & Influenza A virus & IAV & tunneling nanotubes \\
\hline Arenaviridae & Lymphocytic choriomeningitis virus & LCMV & $\begin{array}{l}\text { tunneling nanotubes } \\
\text { actin comets }\end{array}$ \\
\hline
\end{tabular}

the inhibition of actin polymerization, the TNT formation and transfer of viral genome was attenuated, proving the possible strategy of virus dissemination by TNTs (Kumar et al., 2017) (Fig. 4).

\section{Arenaviridae}

Lymphocytic choriomeningitis virus (LCMV) is an RNA virus causing rodent-transmitted persistent infections. It is an important experimental model system to study acute and persistent viral infections, and also a neglected human pathogen of clinical significance (Laposova et al., 2013). Specific strain MX establishes persistent infection without the yielding of infectious virus, using thus cell-to-cell contacts for dissemination. Earlier, we have proved that the viral nucleoprotein interacts with keratin $1(\mathrm{~K} 1)$, which facilitates its transfer preferentially to the desmosomes, tight junctions connecting two adjacent cells. Here the virus can cross the intercellular space to the neighboring cell, protected from the immune system. Also, the presence of the MX strain induced the expression of $\mathrm{K} 1$ and desmosomes (Labudova et al., 2009). K1 is essential for the persistent infection of LCMV strain MX and its absence effectively slowed down the course of infection. The presence of the virus enhanced the $\mathrm{K} 1$ expression, while the presence of $\mathrm{K} 1$ protein potentiated the viral cell-to-cell spread in persistently infected cells (Labudova et al., 2019).

We have also proposed the possibility that the LCMV strain utilizes other types of cell-to-cell transmission. Firstly, the utilization of actin, similarly to the vaccinia virus, as the viral nucleoprotein could be seen on the ends of the actin filaments and the infected cells showed richer actin network. Secondly, inside the TNTs, as we could see the particles travelling along the nanotubes and thirdly, traveling along the protrusions associated with the membrane (Labudova et al., 2018).

During persistent infection, the virus exploits the host cell without disturbing its vital functions. However, microenvironmental hypoxia can disrupt this delicate balance and escalate virus pathogenesis. It was demonstrated that exposure of cells persistently infected with LCMV MX to chronic hypoxia resulted in increased expression of all virus genes in hypoxia inducible factordependent manner (Tomaskova et al., 2011). After the exposure to hypoxia the infectious virions begun to form and a traditional receptor-mediated transmission took place instead (Fig. 4). 


\section{Conclusion}

From many studies it is clearly seen that the viruses don't depend only on the canonic receptor-mediated transmission. They can use many different ways to endure in the cell population even if the most common transmission fails. The viruses from most of the families were able to establish a different path to infect the neighboring cells to survive. They have found the way how to evade the neutralizing antibodies and found a faster way to disseminate. The knowledge about different paths of transmission gives us the possibilities to fight the viruses on both fronts - the classical receptor-mediated and cellto-cell mediated - and may help us to eliminate some of the threatening diseases.

Acknowledgment. This study was supported by grant from the Research and Development Operational Program funded by ERDF (project PV-INF-PAT, ITMS 26240220032).

\section{References}

Ady J, Thayanithy V, Mojica K, Wong P, Carson J, Rao P, Fong Y, Lou E., Mol. Ther. Oncolytics. 3, 16029, 2016. https://doi. org/10.1038/mto.2016.29

Albrecht-Buehler G., J. Cell Biol. 69, 275-286, 1976. https://doi. org/10.1083/jcb.69.2.275

Anderson DJ., J. Infect. Dis. 210 (Suppl. 3), S648-S653, 2014. https://doi.org/10.1093/infdis/jiu537

Andresen V, Wang X, Ghimire S, Omsland M, Gjertsen BT, Gerdes HH., Cell Death. Differ. 20, 1124, 2013. https://doi. org/10.1038/cdd.2013.61

Barre-Sinoussi F, Chermann J, Rey F, Nugeyre M, Chamaret S, Gruest J, Dauguet C, Axler-Blin C, Vézinet-Brun F, Rouzioux C, Rozenbaum W, Montagnier L., Science 220, 868-871, 1983. https://doi.org/10.1126/science.6189183

Baxter AE, Russell RA, Duncan CJ, Moore MD, Willberg CB, Pablos JL, Finzi A, Kaufmann DE, Ochsenbauer C, Kappes JC, Groot F, Sattentau QJ., Cell Host Microbe 16, 711-721, 2014. https://doi.org/10.1016/j.chom.2014.10.010

Boyce M, Roy P., J. Virol. 81, 2179-2186, 2007. https://doi. org/10.1128/JVI.01819-06

Bracq L, Xie M, Benichou S, Bouchet J., Front. Immunol. 9, 260, 2018. https://doi.org/10.3389/fimmu.2018.00260

Brimacombe CL, Grove J, Meredith LW, Hu K, Syder AJ, Flores MV, Timpe JM, Krieger SE, Baumert TF, Tellinghuisen TL, Wong-Staal F, Balfe P, McKeating JA., J. Virol. 85, 596-605, 2011. https://doi.org/10.1128/JVI.01592-10

Callens N, Brugger B, Bonnafous P, Drobecq H, Gerl MJ, Krey T, Roman-Sosa G, Rumenapf T, Lambert O, Dubuisson J, Rouille Y., PLoS Pathog. 12, e1005476, 2016. https://doi. org/10.1371/journal.ppat.1005476

Carloni G, Crema A, Valli MB, Ponzetto A, Clementi M., Curr. Mol. Med. 12, 83-95, 2012. https://doi.org/10.2174/ $\underline{156652412798376152}$
Carmichael JC, Yokota H, Craven RC, Schmitt A, Wills JW., PLoS Pathog. 14, e1007054, 2018. https://doi.org/10.1371/ journal.ppat.1007054

Carpentier DC, Gao WN, Ewles H, Morgan GW, Smith GL., PLoS Pathog. 11, e1004723, 2015. https://doi.org/10.1371/ journal.ppat.1004723

Casartelli N., Curr. Drug. Targets 17, 65-75, 2016. https://doi.org /10.2174/138945011701151217105638

Chen BK., Immunol. Res. 54, 133-139, 2012. https://doi.org/ 10.1007/s12026-012-8320-8

Chen P, Hubner W, Spinelli MA, Chen BK., J. Virol. 81, 1258212595, 2007. https://doi.org/10.1128/JVI.00381-07

Cuddington BP, Mossman KL., J. Virol. 88, 6885-6895, 2014. https://doi.org/10.1128/JVI.00849-14

Dale BM, McNerney GP, Thompson DL, Hubner W, de Los Reyes K, Chuang FY, Huser T, Chen BK., Cell Host Microbe 10, 551-562, 2011. https://doi.org/10.1016/j.chom. 2011.10.015

Dodding MP, Mitter R, Humphries AC, Way M., EMBO J 30, 4523-438, 2011. https://doi.org/10.1038/emboj.2011.326

Dubey GP, Ben-Yehuda S., Cell 144, 590-600, 2011. https://doi. org/10.1016/j.cell.2011.01.015

Favoreel HW, Van Minnebruggen G, Adriaensen D, Nauwynck HJ., Proc. Natl. Acad. Sci. USA 102, 8990-8995, 2005. https://doi.org/10.1073/pnas.0409099102

Gardel ML, Schneider IC, Aratyn-Schaus Y, Waterman CM., Annu. Rev. Cell Dev. Biol. 26, 315-333, 2010. https://doi. org/10.1146/annurev.cellbio.011209.122036

Gerdes HH, Carvalho RN., Curr. Opin. Cell Biol.20,470-475, 2008. https://doi.org/10.1016/i.ceb.2008.03.005

Gill MB, Edgar R, May JS, Stevenson PG., PLoS One 3, e1808, 2008. https://doi.org/10.1371/journal.pone.0001808

Gousset K, Schiff E, Langevin C, Marijanovic Z, Caputo A, Browman DT, Chenouard N, de Chaumont F, Martino A, Enninga J, Olivo-Marin JC, Mannel D, Zurzolo C., Nat. Cell Biol.11,328-336, 2009. https://doi.org/10.1038/ncb1841

Gummuluru S, Pina Ramirez NG, Akiyama H., J. Infect. Dis. 210 (Suppl. 3), S641-S647, 2014. https://doi.org/10.1093/ infdis/jiu442

Guo R, Davis D, Fang Y., Virology 517, 122-134, 2018. https://doi. org/10.1016/j.virol.2017.12.018

Hubner W, McNerney GP, Chen P, Dale BM, Gordon RE, Chuang FY, Li XD, Asmuth DM, Huser T, Chen BK., Science 323, 1743-1747,2009. https://doi.org/10.1126/science.1167525

Humphries AC, Dodding MP, Barry DJ, Collinson LM, Durkin CH, Way M., Cell Host Microbe 12,346-359,2012. https:// doi.org/10.1016/j.chom.2012.08.002

Igakura T, Stinchcombe JC, Goon PK, Taylor GP, Weber JN, Griffiths GM, Tanaka Y, Osame M, Bangham CR., Science 299, 1713-1716, 2003. https://doi.org/10.1126/ science. 1080115

Inaba M, Buszczak M, Yamashita YM., Nature 523, 329-332, 2015. https://doi.org/10.1038/nature14602

Jacquemet G, Hamidi H, Ivaska J., Curr. Opin. Cell Biol. 36, 23-31, 2015. https://doi.org/10.1016/i.ceb.2015.06.007

Jansens RJJ, Van den Broeck W, De Pelsmaeker S, Lamote JAS, Van Waesberghe C, Couck L, Favoreel HW., J. Virol. 91, e00749-17, 2017. https://doi.org/10.1128/JVI.00749-17 
Jolly C, Kashefi K, Hollinshead M, Sattentau QJ., J. Exp. Med.199, 283-293, 2004. https://doi.org/10.1084/jem.20030648

Jolly C, Mitar I, Sattentau QJ., J. Virol. 81, 13916-13921, 2007. https://doi.org/10.1128/JVI.01585-07

Jolly C, Sattentau QJ., Traffic. 5, 643-650, 2004. https://doi. org/10.1111/j.1600-0854.2004.00209.x

Jouvenet N, Windsor M, Rietdorf J, Hawes P, Monaghan P, Way M, Wileman T., Cell Microbiol. 8, 1803-1811, 2006. https://doi.org/10.1111/j.1462-5822.2006.00750.x

Kadiu I, Gendelman HE., J. Neuroimmune. Pharmacol. 6, 658675, 2011a. https://doi.org/10.1007/s11481-011-9298-z

Kadiu I, Gendelman HE., J. Proteome Res. 10, 3225-3238, 2011b. https://doi.org/10.1021/pr200262q

Kijewski SD, Gummuluru S., Future Virol. 10, 257-269, 2015. https://doi.org/10.2217/fvl.15.2

Kinlock BL, Wang Y, Turner TM, Wang C, Liu B., PLoS One 9, e96760, 2014. https://doi.org/10.1371/journal. pone.0096760

Kolesnikova L, Bohil AB, Cheney RE, Becker S., Cell Microbiol. 9, 939-951, 2007. https://doi.org/10.1111/j.14625822.2006.00842.x

Kolesnikova L, Bugany H, Klenk HD, Becker S., J. Virol. 76, 1825-1838, 2002. https://doi.org/10.1128/JVI.76.4.1825$\underline{1838.2002}$

Kornberg TB, Roy S., Development 141, 729-736, 2014. https://doi. org/10.1242/dev.086223

Kumar A, Kim JH, Ranjan P, Metcalfe MG, Cao W, Mishina M, Gangappa S, Guo Z, Boyden ES, Zaki S, York I, GarciaSastre A, Shaw M, Sambhara S., Sci. Rep. 7, 40360, 2017. https://doi.org/10.1038/srep40360

Labarque GG, Nauwynck HJ, Van Reeth K, Pensaert MB., J. Gen. Virol. 81,1327-1334, 2000. https://doi.org/10.1099/00221317-81-5-1327

Labudova M, Ciampor F, Pastorekova S, Pastorek J., Acta Virol. 62, 424-434, 2018. https://doi.org/10.4149/av 2018411

Labudova M, Tomaskova J, Skultety L, Pastorek J, Pastorekova S., J.Virol. 83, 7842-7849, 2009. https://doi.org/10.1128/ JVI.00309-09

Labudova M, Zduriencikova M, Fabianova A, Baratova M, Ditte P, Radvak P, Nemcovicova I, Pastorekova S, Pastorek J., Acta Virol.63, 169-185, 2019. https://doi.org/10.4149/ av_2019_209

Lambert C, Desbarats J, Arbour N, Hall JA, Olivier A, Bar-Or A, Antel JP., J. Immunol.181, 8288-8297, 2008. https://doi. org/10.4049/jimmunol.181.12.8288

Lannes N, Garcia-Nicolas O, Demoulins T, Summerfield A, Filgueira L., Sci. Rep. 9,4833, 2019. https://doi.org/10.1038/ s41598-019-41302-1

Lannes N, Neuhaus V, Scolari B, Kharoubi-Hess S, Walch M, Summerfield A, Filgueira L., Virol. J.14, 8, 2017. https:// doi.org/10.1186/s12985-016-0675-3

Laposova K, Pastorekova S, Tomaskova J., Acta Virol. 57, 160-70, 2013. https://doi.org/10.4149/av_2013_02_160

Law KM, Komarova NL, Yewdall AW, Lee RK, Herrera OL, Wodarz D, Chen BK., Cell Rep. 15, 2771-2783, 2016. https://doi. org/10.1016/j.celrep.2016.05.059

Li H, Zony C, Chen P, Chen BK., J. Virol. 91, 2017. https://doi. org/10.1007/978-981-10-4831-9_6
Liang D, Sainz IF, Ansari IH, Gil LH, Vassilev V, Donis RO., J. Gen.Virol. 84,1269-1274,2003. https://doi.org/10.1099/ vir.0.18557-0

Lindenbach BD, Rice CM., Nature 436, 933-938, 2005. https:// doi.org/10.1038/nature04077

Martinez MG, Kielian M., PLoS Pathog. 12, e1006061, 2016. https://doi.org/10.1371/journal.ppat.1006061

Maurer K, Krey T, Moennig V, Thiel HJ, Rumenapf T., J. Virol. 78, 1792-1799, 2004. https://doi.org/10.1128/JVI.78.4.17921799.2004

McDonald D, Wu L, Bohks SM, KewalRamani VN, Unutmaz D, Hope TJ., Science 300, 1295-1297, 2003. https://doi. org/10.1126/science.1084238

Merwaiss F, Czibener C, Alvarez DE., J. Virol. 93, e01776-18, 2019. https://doi.org/10.1128/JVI.01776-18

Miller J, Fraser SE, McClay D., Development 121, 2501-2511, 1995.

Misra UK, Kalita J., Prog. Neurobiol. 91, 108-120, 2010. https:// doi.org/10.1016/i.pneurobio.2010.01.008

Muylkens B, Thiry J, Kirten P, Schynts F, Thiry E., Vet. Res. 38, 181-209, 2007. https://doi.org/10.1051/vetres:2006059

Naphade S, Sharma J, Gaide Chevronnay HP, Shook MA, Yeagy BA, Rocca CJ, Ur SN, Lau AJ, Courtoy PJ, Cherqui S., Stem Cells 33, 301-309, 2015. https://doi.org/10.1002/ stem. 1835

Newsome TP, Marzook NB., Cell Dev. Biol 46, 155-163, 2015. https://doi.org/10.1016/j.semcdb.2015.10.008

Nikolic DS, Lehmann M, Felts R, Garcia E, Blanchet FP, Subramaniam S, Piguet V., Blood 118, 4841-4852, 2011. https:// doi.org/10.1182/blood-2010-09-305417

Nobiron I, Thompson I, Brownlie J, Collins ME., Vaccine 21, 2082-2092, 2003. https://doi.org/10.1016/S0264410X(02)00745-4

Pedro KD, Henderson AJ, Agosto LM., Virus Res. 265, 115-121, 2019. https://doi.org/10.1016/i.virusres.2019.03.014

Peters CJ., N. Engl. J. Med. 352, 2571-2573, 2005. https://doi. org/10.1056/NEJMp058109

Ramirez-Weber FA, Kornberg TB., Cell 97,599-607,1999. https:// doi.org/10.1016/S0092-8674(00)80771-0

Reh L, Magnus C, Schanz M, Weber J, Uhr T, Rusert P, Trkola A., PLoS Pathog.11, e1004966,2015.https://doi.org/10.1371/ journal.ppat.1004966

Resch W, Hixson KK, Moore RJ, Lipton MS, Moss B., Virology 358, 233-247, 2007. https://doi.org/10.1016/j.virol.2006.08.025

Rietdorf J, Ploubidou A, Reckmann I, Holmstrom A, Frischknecht F, Zettl M, Zimmermann T, Way M., Nat. Cell Biol. 3, 992-1000, 2001. https://doi.org/10.1038/ncb1101-992

Roberts KL, Manicassamy B, Lamb RA., J. Virol. 89, 1537-1549, 2015. https://doi.org/10.1128/JVI.03306-14

Rodriguez-Plata MT, Puigdomenech I, Izquierdo-Useros N, Puertas MC, Carrillo J, Erkizia I, Clotet B, Blanco J, Martinez-Picado J., Retrovirology 10, 42, 2013. https:// doi.org/10.1186/1742-4690-10-42

Roy S, Huang H, Liu S, Kornberg TB., Science 343, 1244624, 2014. https://doi.org/10.1126/science.1244624

Rustom A, Saffrich R, Markovic I, Walther P, Gerdes HH., Science 303, 1007-1010, 2004. https://doi.org/10.1126/ science. 1093133 
Sattentau Q., Nat. Rev. Microbiol. 6, 815-826, 2008. https://doi. org/10.1038/nrmicro1972

Schmeiser S, Mast J, Thiel HJ, Konig M., J. Virol. 88, 2717-2724, 2014. https://doi.org/10.1128/JVI.03237-13

Sherer NM, Lehmann MJ, Jimenez-Soto LF, Horensavitz C, Pypaert M, Mothes W., Nat. Cell Biol. 9, 310-315, 2007. https://doi.org/10.1038/ncb1544

Sherer NM, Mothes W., Trends Cell Biol. 18, 414-420, 2008. https://doi.org/10.1016/i.tcb.2008.07.003

Sigal A, Kim JT, Balazs AB, Dekel E, Mayo A, Milo R, Baltimore D., Nature 477, 95-98, 2011. https://doi.org/10.1038/ nature10347

Sloan RD, Kuhl BD, Mesplede T, Munch J, Donahue DA, Wainberg MA., J. Virol. 87, 8110-8123, 2013. https://doi.org/10.1128/ JVI.00815-13

Souriant S, Balboa L, Dupont M, Pingris K, Kviatcovsky D, Cougoule C, Lastrucci C, Bah A, Gasser R, Poincloux R, Raynaud-Messina B, Al Saati T, Inwentarz S, Poggi S, Morana EJ, Gonzalez-Montaner P, Corti M, Lagane B, Vergne I, Allers C, Kaushal D, Kuroda MJ, Sasiain MDC, Neyrolles O, Maridonneau-Parini I, Lugo-Villarino G, Verollet C., Cell Rep. 26,3586-3599 e7, 2019. https://doi. org/10.1016/j.celrep.2019.02.091

Sourisseau M, Sol-Foulon N, Porrot F, Blanchet F, Schwartz O., J. Virol. 81, 1000-1012, 2007. https://doi.org/10.1128/ JVI.01629-06

Sowinski S, Jolly C, Berninghausen O, Purbhoo MA, Chauveau A, Kohler K, Oddos S, Eissmann P, Brodsky FM, Hopkins C, Onfelt B, Sattentau Q, Davis DM., Nat. Cell Biol. 10, 211-219, 2008. https://doi.org/10.1038/ncb1682

Sun Y, Luo Y, Wang CH, Yuan J, Li N, Song K, Qiu HJ., Vet. Microbiol. 183, 119-124, 2016. https://doi.org/10.1016/j. vetmic.2015.12.008

Takahashi A, Kukita A, Li YJ, Zhang JQ, Nomiyama H, Yamaza T, Ayukawa Y, Koyano K, Kukita T., J. Cell Biochem. 114, 1238-1247, 2013. https://doi.org/10.1002/jcb.24433

Thayanithy V, Babatunde V, Dickson EL, Wong P, Oh S, Ke X, Barlas A, Fujisawa S, Romin Y, Moreira AL, Downey RJ, Steer CJ, Subramanian S, Manova-Todorova K, Moore MA, Lou E., Exp. Cell Res. 323, 178-188, 2014a. https:// doi.org/10.1016/j.yexcr.2014.01.014

Thayanithy V, Dickson EL, Steer C, Subramanian S, Lou E., Transl. Res. 164, 359-365, 2014b. https://doi. org/10.1016/j.trsl.2014.05.011

Thiel HJ, Stark R, Weiland E, Rumenapf T, Meyers G., J. Virol. 65, 4705-4712, 1991. https://doi.org/10.1128/JVI.65.9.4705$\underline{4712.1991}$
Thomas C, Young NJ, Heaney J, Collins ME, Brownlie J., Vaccine 27, 2387-2393, 2009. https://doi.org/10.1016/j.vaccine.2009.02.010

Timpe JM, Stamataki Z, Jennings A, Hu K, Farquhar MJ, Harris HJ, Schwarz A, Desombere I, Roels GL, Balfe P, McKeating JA., Hepatology 47, 17-24, 2008. https://doi. org/10.1002/hep.21959

Titanji BK, Aasa-Chapman M, Pillay D, Jolly C., Retrovirology 10, 161, 2013. https://doi.org/10.1186/1742-4690-10-161

Tomaskova J, Oveckova I, Labudova M, Lukacikova L, Laposova K, Kopacek J, Pastorekova S, Pastorek J., J. Virol. 85, 13069-13076,2011.https://doi.org/10.1128/JVI.00829-11

Trelstad RL, Hay ED, Revel JD., Dev. Biol.16,78-106, 1967. https:// doi.org/10.1016/0012-1606(67)90018-8

Tyborowska J, Bienkowska-Szewczyk K, Rychlowski M, Van Oirschot JT, Rijsewijk FA., Arch. Virol. 145, 333-351, 2000. https://doi.org/10.1007/s007050050026

Uhl J, Gujarathi S, Waheed AA, Gordon A, Freed EO, Gousset K., J. Cell Commun. Signal. 13, 209-224, 2019. https://doi. org/10.1007/s12079-018-0493-z

Van Prooyen N, Gold H, Andresen V, Schwartz O, Jones K, Ruscetti F, Lockett S, Gudla P, Venzon D, Franchini G., Proc. Natl. Acad. Sci. USA 107,20738-20743, 2010. https://doi. org/10.1073/pnas.1009635107

Wang P, Li M, Lu W, Zhang D, Hu Q, Liu Y., Virol. Sin. 32, 495-502, 2017. https://doi.org/10.1007/s12250-017-4034-3

Wang X, Gerdes HH., Cell Death Differ. 22,1181-1191,2015. https:// doi.org/10.1038/cdd.2014.211

Wang X, Veruki ML, Bukoreshtliev NV, Hartveit E, Gerdes HH., Proc. Natl. Acad.Sci. USA 107,17194-17199, 2010. https:// doi.org/10.1073/pnas.1006785107

Wang Y, Cui J, Sun X, Zhang Y., Cell Death Differ. 18, 732-742, 2011. https://doi.org/10.1038/cdd.2010.147

Williams GS, Collinson LM, Brzostek J, Eissmann P, Almeida CR, McCann FE, Burshtyn D, Davis DM., Traffic 8, 1190-204, 2007.https://doi.org/10.1111/j.1600-0854.2007.00603.x

Witteveldt J, Evans MJ, Bitzegeio J, Koutsoudakis G, Owsianka AM, Angus AG, Keck ZY, Foung SK, Pietschmann T, Rice CM, Patel AH., J. Gen. Virol. 90, 48-58, 2009. https://doi. org/10.1099/vir.0.006700-0

You R, Li X, Xu Y, Liu Y, Lu S, Li M., Materials (Basel) 7, 4628-4639, 2014. https://doi.org/10.3390/ma7064628

Yun SI, Choi YJ, Yu XF, Song JY, Shin YH, Ju YR, Kim SY, Lee YM., J. Neurovirol. 13, 522-535, 2007. https://doi. org/10.1080/13550280701684651

Zhong P, Agosto LM, Munro JB, Mothes W., Curr. Opin. Virol. 3, 44-50,2013.https://doi.org/10.1016/j.coviro.2012.11.004 